The $B D J$ News section accepts items that include general news, latest research and diary events that interest our readers.

Press releases or articles may be edited, and should include a colour photograph if possible. Please direct your correspondence to the News Editor, Arveen Bajaj at the BDJ, The Macmillan Building, 4 Crinan Street, London N1 9XW or by email to bdj@bda.org

\section{Gender makes a difference}

Wounds in the mouth heal more slowly in women and older adults, a new study at the University of Illinois at Chicago (UIC) reveals. Researchers found that while wounds to the skin heal more quickly in women than in men, the opposite is true for healing of wounds inside the mouth. Dr Phillip Marucha, Head of Periodontics at the UIC College of Dentistry said, "We discovered that, regardless of age, men's mouth wounds heal faster than women's."

Older women were at the highest risk for delayed healing, their wounds closing half as slowly as younger men, and Dr Marucha believes that the findings of the study could have important implications for surgical practices.

"There are an increasing number of surgical procedures being performed in older populations and a greater emphasis needs to be placed on accelerating the healing process" he explained.

The study involved creating a small, standardised circular wound, half the diameter of a pencil, between the first and second molar of 212 male and female volunteers aged 18 to 35 years and 50 to 88 years.

Professor Christopher Engeland, Research Assistant Professor at UIC and lead author of the study suggests that testosterone may help mouth wounds heal faster in men. He explained that it is a potent anti-inflammatory hormone that is abundant in saliva and added that while women are generally more prone to inflammatory diseases, such as rheumatoid arthritis, women's wounds heal faster than men's in part because inflammation causes them to close faster. But the more inflammation a person has inside the mouth, the slower wounds appear to heal.

\title{
BDJ Eastman online CPD registers 10,000th participant
}

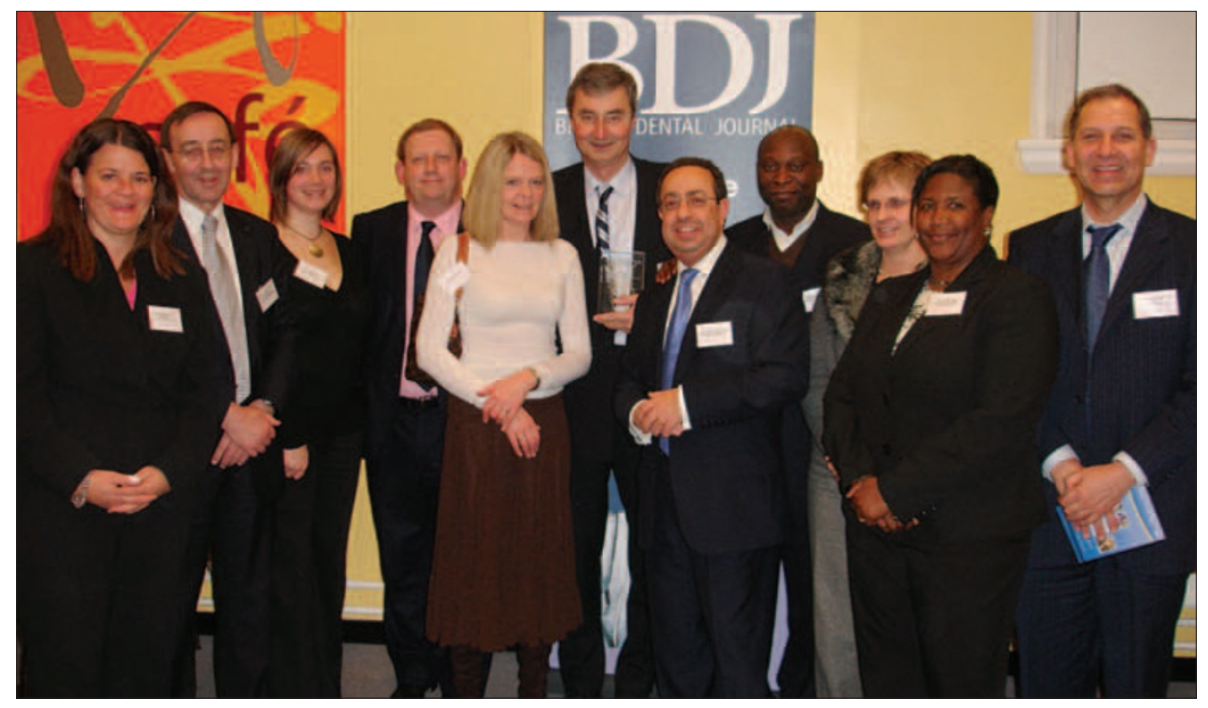

The $B D J$ Eastman Online CPD Programme has enrolled its 10,000th registered user. Dr Michael Hickley was presented with a glass trophy by Peter Ward, Chief Executive of the BDA, to reflect his registration as the 10,000th participant at a reception hosted by Professor Crispian Scully CBE, Dean of the Eastman Dental Institute, last month.

This followed a short presentation given by Professor Andrew Eder, Director of Education at the Eastman, who formally thanked everyone at Nature Publishing, the BDJ, the Eastman and Smile-on Ltd who have been actively involved in supporting and developing this innovative programme since its inception. There are now over 3,000 dentists accessing the site every month to submit answers online.

Pictured above from left to right, Kim Black-Totham, BDJ Publisher, Nature Publishing, Professor Crispian Scully CBE, Dean, UCL Eastman Dental Institute, Rowena Milan, Editor, BDJ, Dr Peter Ward, Chief Executive, British Dental Association, Mrs Penny Hickley, Dr Michael Hickley, 10,000th Participant, Professor Andrew Eder, Director of Education, UCL Eastman Dental Institute, Michael Seriki, Commercial Director, Smile-on Ltd, Josephine Carr, Business \& Administration Manager, UCL Eastman CPD, Marjorie Kelly, Programme Administrator, UCL Eastman CPD and Noam Tamir, CEO, Smile-on Ltd.

\section{Manifesto launched}

The British Dental Association (BDA) this month launched the BDA Northern Ireland 2007 manifesto for dentistry. It is calling on those elected to the new Northern Ireland Assembly in March to address the poor state of the nation's teeth and mouths. Northern Ireland currently suffers worse oral health than the
Republic of Ireland, England, Scotland and Wales. The BDA also stressed the possibility for fundamental change presented by the 2006 Primary Care Dental Care Strategy and called upon the assembly to ensure that any new arrangements improve access for patients, allow high street dentists more time to focus on preventative care and provide additional funding for dentistry. 


\section{Report shows up inequalities in children's dental health}

Screening school children for tooth decay should be scrapped because it does not improve dental health according to the results of a recent Oral Health Unit (OHU) study. The study has led to a possible change in government policy regarding the dental care of all school children in England and Wales.

The OHU undertook a randomised control trial of 17,000 children to find out if screening reduced untreated tooth decay and increased dental attendance of children in the whole population.

Results showed that only a quarter of children who were identified as having decay in their permanent teeth went on to receive appropriate treatment. Whilst higher numbers of children from disadvantaged backgrounds had tooth decay, more children from affluent backgrounds with decay visited the dentist and received treatment after being screened at school.

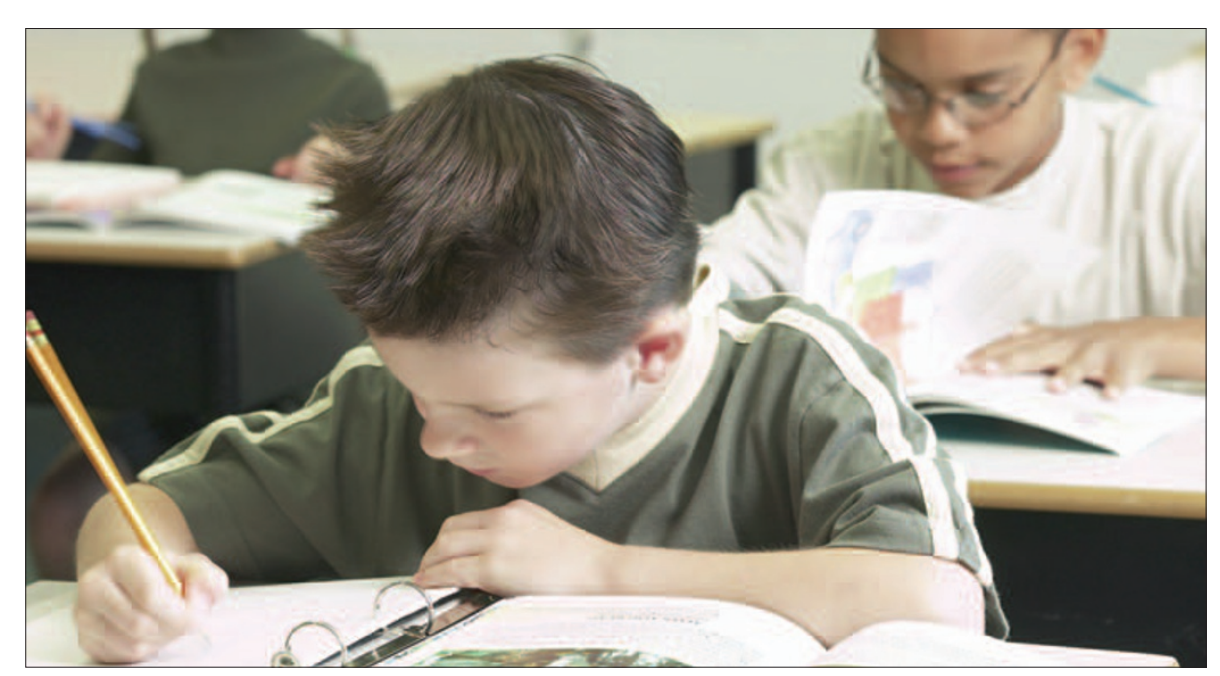

The study looked at the dental care of school children in England and Wales

OHU Operational Director, Dr Keith Milsom, said, "These results are important. We found no differences in increases in tooth decay levels in either the first or permanent teeth in children who did and did not receive screening. Also school dental screening in an area where NHS dentistry for children was freely available did not improve dental attendance. It is also probable that the screening programme may even exacerbate inequalities in the use of dental services."

The UK National Screening Committee has now recommended to the UK Chief Dental Officers that there is no evidence to support the continued use of dental screening. New guidance was issued to the NHS in January 2007 recommending that PCTs consider whether or not to continue local screening programmes and, if not, how best to address inequalities in oral health in other ways and use resources more effectively.
Call for tighter controls to ensure patient safety

UK healthcare professional regulators have called for the European Commission to propose a new legal duty on bodies with similar roles across Europe to exchange disciplinary and registration information about healthcare professionals and to act on it.

Media attention around healthcare in Europe has largely, to date, focused on the potential for increased numbers of patient 'tourists'. However, there is already a significant level of mobility of healthcare professionals across European borders. In 2005 , over 7,000 practitioners from the EEA came to the UK to register with members of the Alliance of UK Health Regulators on Europe (AURE), a coalition of all ten UK health and social care professional regulators, and find work.

This call has been made in a joint response to the European Commission's consultation regarding Community Action on Health Services by AURE members.

Hew Mathewson, President of the UK's General Dental Council, one of AURE's coalition members said, "With this scale of mobility of dentists, nurses, doctors and other healthcare professionals across European borders, much greater information needs to be made available to patients, the public and health professionals alike. National regulators must be enabled to facilitate this free moment, but also to ensure the safety of patients and the public." 


\section{New honorary appointment}

Colonel (Retd) James Hardy assumed the appointment of Colonel Commandant of the Royal Army Dental Corps (RADC) on $1^{\text {st }}$ January 2007 following the retirement of Colonel Tony Hawkes as Colonel Commandant.

Colonel Hardy retired from the Royal Army Dental Corps after 36 years service in 2001, and has since been employed as a full time civilian dental practitioner working for the Defence Dental Service.

The appointment of Colonel Commandant is an honorary appointment approved by Her Majesty the Queen. Colonel Hardy's main responsibilities will be to help guard Corps traditions, to foster esprit-de-corps and to represent Corps interests.

Colonel Hardy said it was a great honour to have been appointed Colonel Commandant of the Royal Army Dental Corps especially at a time when the armed forces, including his own Corps, were under ever increasing pressure as a result of their commitment to operational deployments.

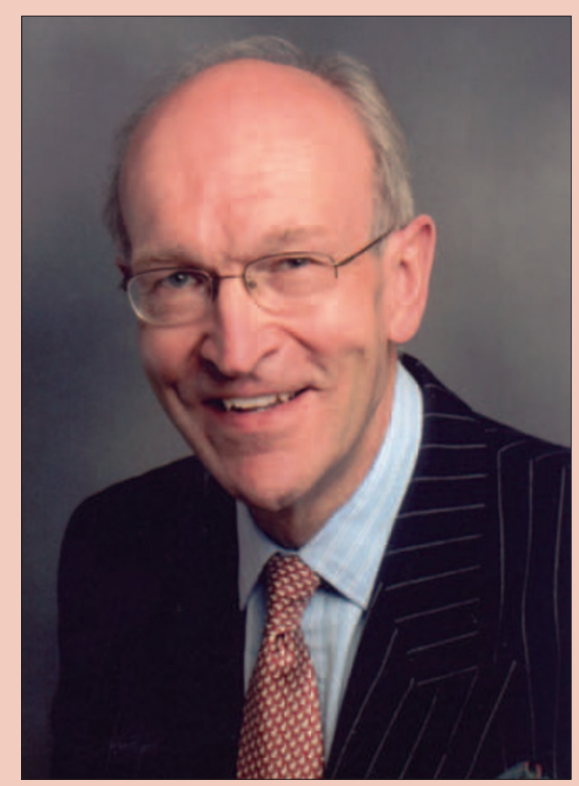

\section{Top names at Young Dentist Conference}

This year's Young Dentist Conference was a sell out success for the second year running. The conference was a joint collaboration between the British Dental Journal and Dental Protection and featured some of the UK's most exciting speakers who mixed essential information for those at the start of their career with humour and experience.

One of the reasons for the conference's popularity with VT groups from all over the country, as well as other recently registered members of the profession, was the speakers' emphasis on how various issues impacted upon young dentists.

The programme's speakers covered topics including relationships and the man-

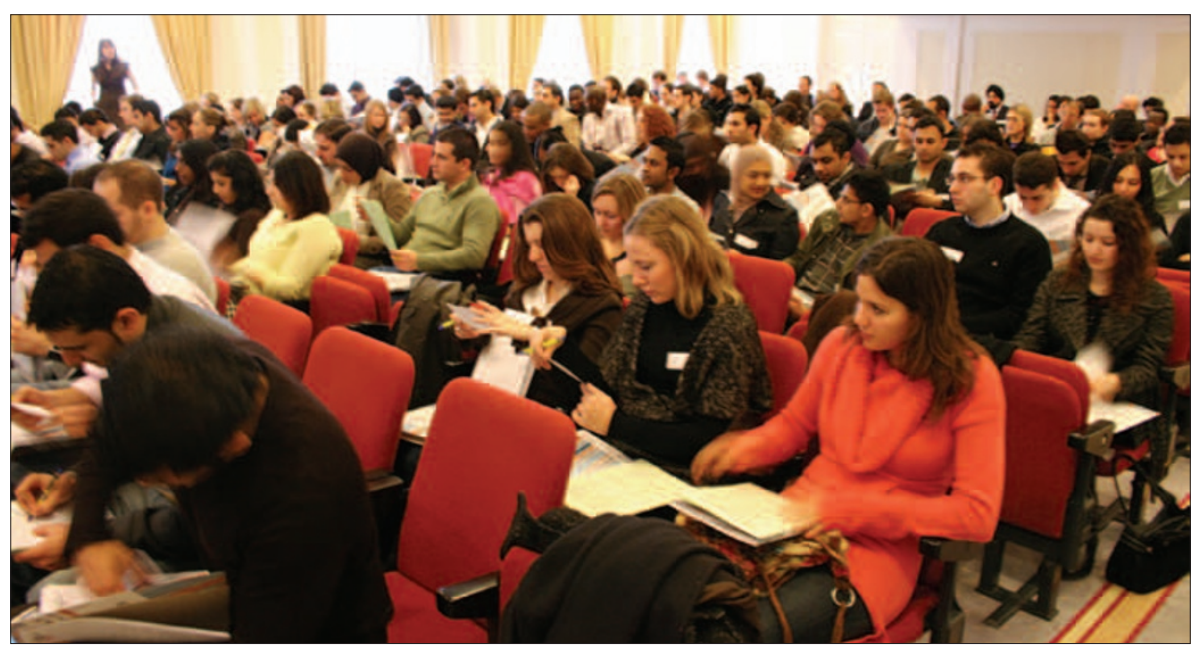

Prosthesis small enough to fit in teeth

Regular pill-taking is soon to become a thing of the past according to scientists in an EU consortium who have developed a new prosthesis that releases the correct dosage of the required medicine on a continuous basis. It is designed to help to avoid the peak concentrations that occur on taking pills, aggravating side effects.

The Intellidrug prosthesis is small enough to fit into two artificial molars, unlike existing drug prostheses and implants. Inside the patient's mouth, it is readily accessible and can easily be maintained and refilled.

The dental prosthesis consists of a drug-filled reservoir, a valve, two sensors and several electronic components, explains Dr Oliver Scholz of the Fraunhofer Institute for Biomedical Engineering (IBMT) in St Ingbert, Germany, where the sensors and electronics were developed.

Saliva enters the reservoir via a membrane, dissolves part of the solid drug and flows through a small duct into the mouth cavity, where it is absorbed by the mucous membranes in the patient's cheeks.

The duct is fitted with two sensors that monitor the amount of medicine being released into the body. One is a flow sensor that measures the volume of liquid entering the mouth via the duct, while the other measures the concentration of the agent contained in the liquid. Based on the measurement results, the electronic circuit either opens or closes a valve at the end of the duct to control the dosage. If the agent has been used up, the electronic system alerts the patient via a remote control, which was also developed at the IBMT. This control permits wireless operation of Intellidrug, and can be used by the patient or doctor to set the dosage required.

The patient has to have the agent refilled every few weeks. This could be done using a deposit system whereby the patient swaps the empty prosthesis for a newly refilled one. At the same time, the battery could be replaced and the device could be serviced, says Dr Scholz. Intellidrug is to undergo clinical testing this year - filled with a drug called Naltrexon, which is taken by drug addicts undergoing withdrawal therapy. 


\section{Reform to the regulation of health professionals}

IAAFA Annual Conference and Exhibition 2007

Date: 16-17 March 2007

Venue: Marriott Hotel, Regents Park, London Email:info@iaafa.net

www.iaafa.net

Healthcare Computing 2007 conference Date: 19-21 March 2007

Venue: Harrogate

www.health-informatics.org/

April

The Society of Manchester Dental Alumni (SOMANDA) biennial meeting and reunion Date: 20 April 2007

Venue: University of Manchester

Email: carolynstylianou@ntlworld.com

The International Team for Implantology

(ITI) World Symposium 2007

Date: 26-28 April 2007

Venue: New York City

www.iti.org

May

ADI 20th Anniversary Congress

Date: 3-5 May 2007

Venue: ICC in Birmingham

www.adi.org.uk

International Osteology Symposium 2007 Date: 10-12 May 2007

Venue: Grimaldi Forum, Monaco

www.osteology-monaco.org

DSTG Annual Symposium 2007

Date: 15 May 2007

Venue: Birmingham Dental Hospital

www.dstg.co.uk

BDA British Dental Conference and

Exhibition 2007

Date: 24-26 May 2007

Venue: Harrogate International

Centre (HIC)

Tel: 02075634590

Email: events@bda.org

June

14th Annual Congress of the Turkish

Dental Association

Date: 11-17 June 2007

Venue: Lütfi Kirdar Convention Center

Istanbul, Turkey

www.tdbkongresi.com

113th Meeting of the American Dental Society of Europe

Date: 26-29 June 2007

Venue: Cameron House, Loch Lomond,

Scotland

Tel: 01413310088

www.adse.co.uk

\section{Death notice}

We are sad to have to announce the death of Jack Messing who died in January.
The government has published a white paper on how to regulate health professionals and ensure patient safety in the UK. As part of this, all health professionals will be required to prove their fitness to practice every five years.

Some of the main proposals in Trust, Assurance and Safety, The Regulation of Health Professionals in the 21st Century, are that professional regulators will be independent of government and led by an equal partnership of independently appointed professionals and members of the public, all health professionals will be required to demonstrate periodically that they are fit to practise by revalidating their professional registration and a move from the criminal

\section{Integrating oral health}

For the first time since 1981, oral health was on the agenda at the World Health Organisation's (WHO) Executive Board Meeting in Geneva. The WHO's Global Oral Health Programme prepared an extensive report entitled Oral Health: action plan for promotion and integrated disease prevention.

Dr Margaret Chan, the newly elected Director-General of the WHO, said that oral diseases are a "neglected area of international health", despite their huge impact on wellbeing and economies, particularly in low and middle-income countries. "The tools and best practices are there and we need to ensure that they are applied and implemented," she added. Member states urged WHO to allocate more resources to matters of oral health and integrated disease prevention.

The President of the FDI World Dental Federation, Dr Michèle Aerden, addressed the WHO Board and recognised the important strategic principles mentioned in the report. The FDI supports the integration of oral health into general health promotion and is keen to involve the dental profession as an active and responsible partner in integrated disease prevention. "By reducing the risks common to many chronic diseases, such as smoking or high sugar consumption, we do not only improve oral health but also other chronic diseases such as diabetes or cardio-vascular diseases," said Dr Aerden in her statement.

The report cited oral disease as a standard of proof to the civil standard with a sliding scale in fitness to practice cases.

The General Dental Council (GDC) has welcomed the white paper and intends to consider the proposals in more detail, such as looking at how a smaller Council can effectively regulate all groups of dental professionals across the UK and introducing an appointments system for all Council members.

However the British Dental Association (BDA) is concerned that two changes to the membership of the GDC - the loss of the professional majority and the appointment, rather than election, of members - may undermine the profession's confidence in the system.

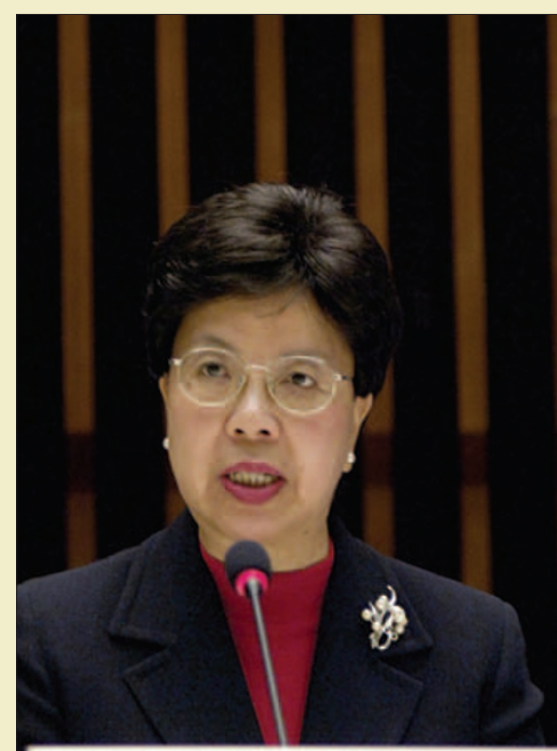

DIRECTOR-GENERAL

Dr Chan says oral diseases are a neglected area of international health.

serious public health problem, linking periodontal disease and tooth loss to other chronic diseases and oral cancer to such lifestyle determinants as tobacco and alcohol consumption.

The proposed action plan for oral health will be discussed at the upcoming World Health Assembly in May 2007 in Geneva. The FDI will encourage, facilitate and coordinate activities and initiatives on this historic occasion. 